\title{
Desenvolvimento de produtos utilizando lona de banner: experiência de um projeto de extensão no Noroeste do Paraná
}

\author{
Product development using banner canvas: experience of an extension project in Northwest Parana \\ Desarrollo de produto utilizando lienzos de banner: experiencia de un proyecto de extensión en el
} noroeste de Paraná

Maiara de Oliveira Santos

ORCID: https://orcid.org/0000-0001-5963-8162 Universidade Estadual de Maringá, Brasil

E-mail: mai.osantos@gmail.com

Danielle Comitre Thomaz

ORCID: https://orcid.org/0000-0002-5091-3954 Universidade Estadual de Maringá, Brasil

E-mail: daniellecomitret@gmail.com

Thalia Emanoele da Silva Oliveira ORCID: https://orcid.org/0000-0001-5261-7924 Universidade Estadual de Maringá, Brasil E-mail: thalia.appelle@gmail.com

Bruna Batista

ORCID: https://orcid.org/0000-0003-3039-826X Universidade Estadual de Maringá, Brasil E-mail: bruna_bathista@hotmail.com Ana Beatriz Avelino Barbosa ORCID: https://orcid.org/0000-0002-3589-2032 Universidade Estadual de Maringá, Brasil E-mail: ra107037@uem.br

Cláudia Cirineo Ferreira Monteiro ORCID: https://orcid.org/0000-0003-4212-7635 Universidade Estadual de Maringá, Brasil E-mail: ccfmonteiro@uem.br

\section{Resumo}

A larga utilização do policloreto de vinila (PVC) para a produção dos mais diversos tipos de produtos em função de sua versatilidade e baixo custo, torna este material um dos mais utilizados pelas indústrias, mas por outro lado gera um expressivo impacto ambiental, seja durante sua produção e principalmente no descarte. As lonas vinílicas utilizadas para banners de congressos e propaganda, que normalmente são utilizadas por períodos muito curtos, são feitas de PVC e outros componentes, o que dificulta seu processo de reciclagem, além disso, quando são descartadas em aterros, levam anos para se decompor. Diante da necessidade de encontrar alternativas sustentáveis, este artigo tem por objetivo reaproveitar lonas de banner para a construção de bolsas e acessórios por meio de cursos de extensão oferecidos as comunidades do Noroeste paranaense, visando o aumento do ciclo de vida deste material feito a base de PVC. Os principais resultados obtidos evidenciaram a viabilidade da produção dos artefatos empregando os banners usados como principal matéria-prima. Por fim, concluiu-se que ao mesmo tempo que o projeto contribuiu para redução do impacto ambiental do descarte do material, por outro lado contribuiu como mais uma alternativa de renda aos artesãos.

Palavras-chave: Design; Lona de banner; Reaproveitamento.

\begin{abstract}
The wide use of polyvinyl chloride (PVC) for the production of the most diverse types of products due to its versatility and low cost, makes this material one of the most used by industries, but on the other hand it generates a significant environmental impact, whether during their production and mainly in the disposal. The vinyl canvas used for congress and advertising banners, which are normally used for very short periods, are made of PVC and other components, which makes it difficult to recycle. Furthermore, when they are discarded in landfills, they take years to decompose. In view of the need to find sustainable alternatives, this article aims to reuse banner tarps for the construction of bags and accessories through extension courses offered to communities in the northwest of Paraná, aiming at increasing the life cycle of this material made from PVC. The main results obtained showed the viability of producing the artifacts using the banners used as the main raw material. Finally, it was concluded that at the same time that the project contributed to reducing the environmental impact of the disposal of the material, on the other hand it contributed as another income alternative for craftsman.
\end{abstract}


Keywords: Design; Banner canvas; Reuse.

\section{Resumen}

El amplio uso del cloruro de polivinilo (PVC) para la fabricación de diversos tipos de productos debido a su versatilidad y bajo coste, hace que este material sea uno de los más utilizados por las industrias, pero por otro lado genera un importante impacto ambiental, tanto durante su producción como especialmente en su eliminación. Las lonas de vinilo utilizadas para congresos y pancartas publicitarias, que suelen utilizarse durante periodos muy cortos, están hechas de PVC y otros componentes, lo que dificulta su proceso de reciclaje, además, cuando se desechan en los vertederos, tardan años en descomponerse. Ante la necesidad de encontrar alternativas sostenibles, este artículo pretende reutilizar la lona de las banderas para la construcción de bolsos y accesorios a través de cursos de extensión ofrecidos a las comunidades del noroeste de Paraná, con el objetivo de aumentar el ciclo de vida de este material fabricado con PVC. Los principales resultados obtenidos mostraron la viabilidad de la producción de artefactos empleando las pancartas usadas como principal materia prima. Finalmente, se concluyó que, al mismo tiempo que el proyecto contribuía a reducir el impacto ambiental de la eliminación del material, por otro lado, contribuía como alternativa de ingresos para los artesanos.

Palabras clave: Diseño; Lienzo de banner; Reutilizar.

\section{Introdução}

Todo produto, independentemente de seu material, provoca impactos ao meio ambiente, seja por meio da sua produção, pelas matérias-primas utilizadas ou ainda durante seu uso ou descarte. Para contribuir com a redução dos impactos ambientais é utilizada a análise do ciclo de vida, um processo para avaliação dos aspectos ambientais associados a um produto que abrange etapas que vão desde a retirada das matérias-primas que entram no sistema produtivo até o descarte do produto final (Manzini e Vezzoli, 2002).

Nesta mesma linha, Peltier e Saporta (2009) afirmam que a sustentabilidade também está diretamente ligada ao ciclo de vida dos produtos, desde a extração e produção de matérias-primas, até a fabricação e preenchimento das embalagens, incluindo venda e o consumo, e a destinação dos resíduos de embalagens. Para Kazazian (2005), cada produto possui um ciclo de vida, que expressa sua existência e garante a evolução da produção e da matéria, e para Fullana e Puig (1997), analisar o impacto de um determinado produto na natureza consiste basicamente em estabelecer a reciclagem, reuso e até mesmo a melhor forma de disposição final de um produto.

De acordo com Rutiaga et al. (2005), os plásticos convencionais são obtidos a partir de polímeros sintéticos derivados de petróleo e, por este motivo, constituem um problema ambiental devido a sua elevada estabilidade. Dentre os produtos que causam impacto no meio ambiente, destaca-se o descarte de banners e faixas publicitárias. O principal material utilizado para confecção de banners e faixas de campanhas publicitárias, congressos e eventos sazonais é a lona vinílica. Material este que, composto de policloreto de vinila (PVC), possui um tempo de decomposição longo sendo que pode chegar a centenas de anos (Cardoso et al., 2016).

De acordo com Plastics Europe (2020) na Europa o PVC é o terceiro polímero mais utilizado para produtos plásticos como equipamentos médicos, brinquedos, móveis, carros e na construção civil e contém as maiores quantidades de aditivos, especialmente ftalatos (Henkel, Hüffer \& Hofmann, 2019).

Para Ashby e Jonhson (2011) e Abir, Abdel-Naby e Al-Ghamdi (2014) o PVC é um dos materiais mais baratos e versáteis para emprego na produção de diversos produtos, entretanto apresenta um elevado impacto ambiental uma vez que seu monômero, cloreto de vinila, é extremamente agressivo ao ambiente, por este motivo vem sofrendo grande pressão para interrupção de sua produção. Portanto, nota-se a necessidade de um destino apropriado para as lonas após o fim de seu uso, que não sejam os aterros.

Visto que a utilização dos banners e faixas, em sua maior parte, é feita para períodos curtos, de um dia a uma semana, o acúmulo desse material é considerável e seu descarte nem sempre é feito de forma adequada. Segundo Najeliski, Palhano e Matoso (2017) ainda possui um agravante pois devido a dificuldade da reciclagem, o material é enviado aos aterros sanitários sem nenhuma separação ou aproveitamento. Jung et al. (2015, p. 04) afirmam que [...] a presença das lonas nas células do aterro 
interfere no processo de decomposição da matéria orgânica devido a formação de camadas impermeáveis que dificultam as trocas gasosas, importantes para as reações de oxidação.

Segundo Jung et al. (2015), as lonas possuem diversas gramaturas e podem ser construídas em material opaco ou não, além disso, também pode haver variações em sua flexibilidade. Além de que, as lonas que já passaram pela etapa da impressão não apresentam a capacidade de realizar o mesmo processo em seu verso. As mesmas são construídas de material resistente, e também podem ser térmicas e impermeáveis. Atualmente, estas também possuem uma qualidade de impressão alta (Rocha; Rosa \& Cardoso, 2009).

Dessa forma, o desenvolvimento de produtos reaproveitando esses materiais para que não sejam descartados torna-se importante para que prolonguem seu ciclo de vida, o que também colabora para a redução dos impactos ambientais causados pelo acúmulo ou descarte incorreto das lonas.

Face ao exposto e considerando que nas regiões de Maringá e Cianorte ocorrem diversos eventos sazonais ligados a indústria da moda, e a eventos científicos, nos quais existe o uso de tal material, percebeu-se a possibilidade de engajar comunidades carentes para, através do desenvolvimento de produto, prolongar o ciclo de vida desse material transformando-o em novos acessórios e gerando renda para a comunidade que o desenvolve.

Desta forma este artigo apresenta os resultados do projeto de extensão universitário que objetivou realizar ações extensionistas visando possibilitar o aumento de renda de famílias e/ou associações de artesãos por meio do aproveitamento de materiais e prolongando o ciclo de vida do produto por meio de uma possível economia circular aplicada, na qual o artesão se torna um agente potencializador de reciclagem.

\section{Metodologia}

A metodologia empregada no projeto foi, inicialmente uma pesquisa exploratória para conhecer o estado da arte do material a ser utilizado, o que compreendeu um levantamento bibliográfico (Silva \& Menezes, 2001). Na sequência foi realizado desenvolvimento de produtos utilizando as ferramentas criativas descritas por Baxter (2005) e finalmente a parte prática com os cursos de extensão.

Todos os materiais utilizados no projeto foram recebidos de doações, os banners são doações da própria instituição, e de eventos publicitários. Os tecidos utilizados para a produção dos produtos foram doados por uma indústria de confecção, e alguns aviamentos foram doados pelas alunas do projeto.

Quando chegam no projeto, os banners são desmontados e seus componentes (lona, bastões, cordões e sapatilhas) são higienizados e guardados até o momento da construção de novos produtos. Os tecidos são organizados por tipos, ou seja, algodão, viscose, malha, entre outros.

A metodologia para a execução do projeto foi baseada no planejamento e organização de materiais e processos de fabricação possíveis que estejam em concordância com a utilização da lona de banner, de forma viável e acessível para que o público-alvo conseguisse realizar. Sendo que tudo foi aplicado em metodologias que serviram posteriormente para o desenvolvimento de cursos, com o passo a passo de cada produto feito.

Também foram realizadas reuniões com representantes das associações de artesãos dos municípios atendidos pelo projeto a fim de convidar os artesãos a participar das palestras, bem como identificar os principais produtos desenvolvidos por eles e a apresentação de alguns produtos já feitos pelo projeto.

Palestras foram oferecidas aos artesãos para conscientização do projeto, nestas palestras foram contabilizados os interessados e montado um plano para o desenvolvimento dos produtos, já que cada grupo interessado possuía características e conhecimentos diferentes entre si.

Além das palestras foram realizados os cursos com os artesãos a fim de familiarizá-los com os diversos tipos de materiais 
que poderiam ser reaproveitados, bem como foram apresentadas as possibilidades de produtos que poderiam ser fabricados.

Os cursos que foram ministrados para as comunidades locais foram nos seguintes temas:

- Impacto ambiental no descarte inadequado de materiais;

- Desenvolvimento de produtos utilizando materiais descartados: o emprego de design ambiental em benefício do meio ambiente e da comunidade local;

- Técnicas de Composição no desenvolvimento de produtos: teoria e prática;

- Técnicas de Serigrafia no desenvolvimento de produtos: teoria e prática;

- Técnicas de Modelagem no desenvolvimento de produtos: teoria e prática;

- Corte e costura;

- Embalagem, marca e comercialização.

\section{Resultados e Discussão}

O projeto iniciou-se em outubro de 2018 com a contratação de um estilista recém formado, e estudantes dos cursos de Moda e Design de Produto e, na sequência o planejamento das atribuições de cada bolsista. O primeiro obstáculo foi entender quais produtos seriam desenvolvidos e quais as técnicas poderiam ser utilizadas, uma vez que nenhum dos integrantes do projeto possuía experiência no uso de lona de banner para produção de produtos.

Assim sendo, foi realizado um brainstorming, seguindo o descrito por Baxter (2005), com as principais ideias de produtos a serem desenvolvidos e a equipe definiu que os testes iniciaram por bolsas e sacolas. Os alunos de moda mais experientes ficaram com a responsabilidade de produzir uma bolsa simples em um modelo já conhecido para tentar perceber quais eram as limitações do material quanto aos tipos de costura poderiam ser feitos, tipos de cortes e ângulos. Desenvolvida a primeira bolsa, foi produzido uma mochila (Figura 1).

Figura 1 - Mochila.

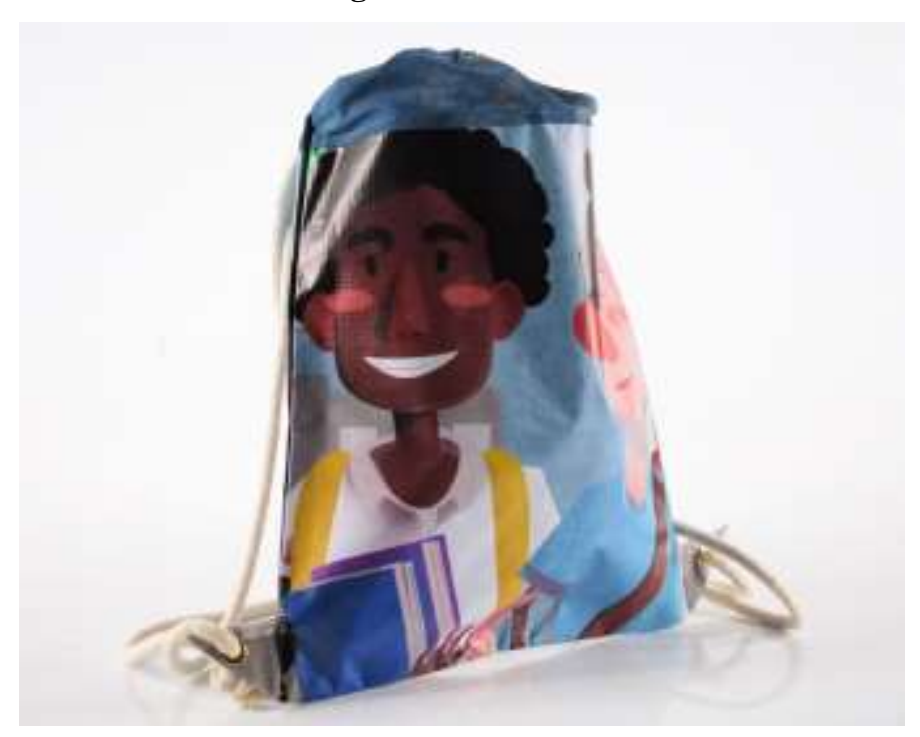

Fonte: Autoras (2021).

As principais limitações encontradas na produção da bolsa e da mochila foram: tipo de linha, limitação quanto aos recortes e ângulos, espessura do material e principalmente a impossibilidade de errar. A linha de algodão não é resistente o suficiente para costurar a lona, ela deixa folgas e arrebenta com facilidade, a solução foi a troca da linha de algodão pela de poliéster. Certos recortes e ângulos não são possíveis de serem feitos porque a lona é grossa, não permitindo virar do avesso para 
o lado certo, processo mais utilizado na confecção de bolsas, pois essa ação danifica o material. A espessura do material limita certas aplicações, mas não impede seu uso, o que deve ser feito é o planejar adequadamente o produto, com isso pode ser feita a escolha adequada da lona, já que são encontradas em diversas espessuras.

Outra limitação do produto é que a lona não permite erros de costura, ou seja, uma vez que a costura seja desfeita, os buracos aparecem comprometendo a imagem do produto. (Figura 2) No entanto esse fator não inutiliza o material completamente, visto que pode ser utilizado para a confecção de produto menor, por exemplo.

Figura 2 - Erros na costura.

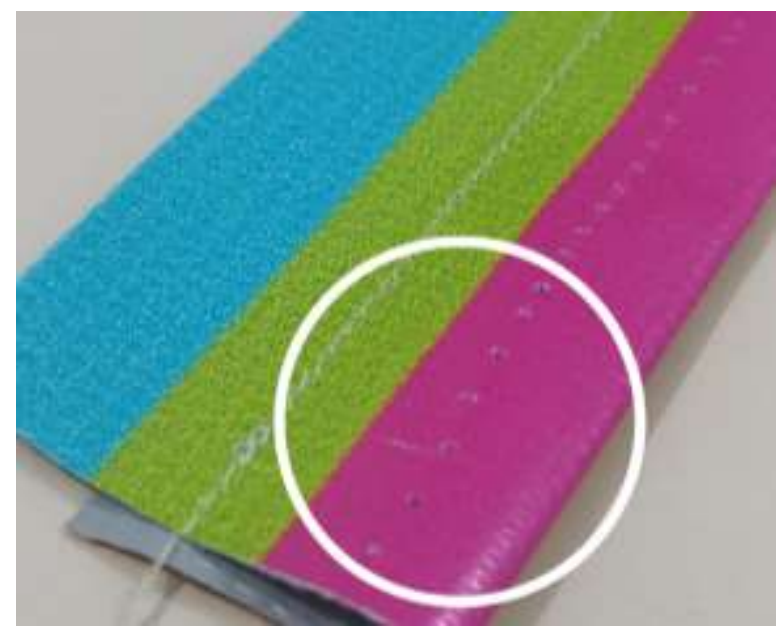

Fonte: Autoras (2021).

Outros testes foram importantes como, por exemplo, os tipos de cola que poderiam ser utilizados na lona, bem como os tipos de tinta que a lona aceita. Foram testadas várias colas como as de contato, instantânea, silicone, branca e a que mostrou melhor resultado foi a Tek Bond 793. Também foram testados vários tipos de tintas como a tinta acrílica, óleo, guache, de tecido, serigráfica e a que apresentou melhor resultado foi a tinta acrílica. Por fim foi elaborado um manual com os tipos de tinta e colas utilizadas na lona.

Para a fabricação dos acessórios como brincos, pulseiras e colares percebeu-se que o acabamento da peça depende do tipo de produto utilizado para o corte. O estilete, por exemplo, pode deixar lascas que comprometem o acabamento, se fazendo necessário a utilização de equipamentos mais específicos para um acabamento ideal de acordo com o tipo de acessório definido.

Após vários meses testando o material e desenvolvendo diversos produtos como bolsas, brincos, colares e objetos de decoração, a equipe estava pronta para ministrar os primeiros cursos. (Figura 3) 
Figura 3 - Produtos desenvolvidos com lona.

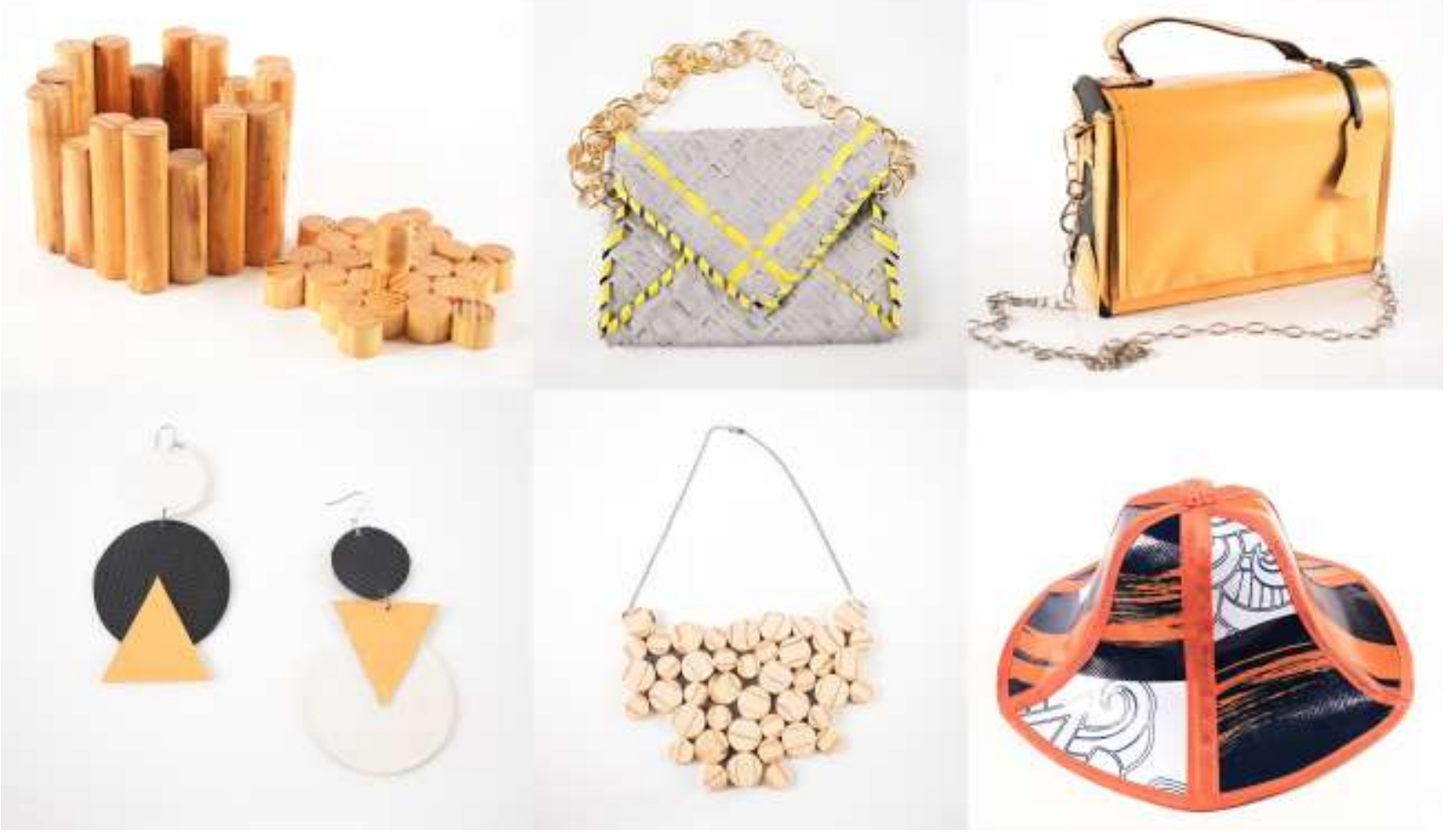

Fonte: Autoras (2021).

Para iniciar os cursos foi realizada uma reunião com membros da comunidade de artesãos das cidades de Cianorte e São Tomé, neste primeiro encontro foi explicado aos artesãos o que era o projeto e seus objetivos.

$\mathrm{Na}$ sequência foram realizados os cursos descritos acima, sempre trabalhando com aulas teóricas e práticas, uma vez que os participantes do curso são artesãos que trabalham durante todo o dia. No primeiro dia além da teoria que tratava sobre a importância de se aproveitar a lona de banner, bem como sobre a consciência ambiental, os alunos do curso puderam conhecer os produtos desenvolvidos pelo projeto e, na sequência foram convidados a pensar em produtos que poderiam ser utilizados com a lona de banner dentro do portfólio de produtos que eles produzem.

No segundo dia os alunos tiveram aula sobre técnicas de composição no desenvolvimento de produtos com lona de banner. Neste dia os alunos aprenderam sobre como o uso das cores pode contribuir para o desenvolvimento de produtos e algumas técnicas de composição foram utilizadas na aula prática, nesta atividade o desafio era a limitação das lonas disponíveis, como eles poderiam utilizar somente as cores disponibilizadas para produzir o mesmo produto sugerido, usando como diferencial a cor.

No terceiro dia do curso os alunos aprenderam sobre técnicas de impressão (serigrafia, estêncil e carimbo) no desenvolvimento de produtos. Esta aula prática ensinou os artesãos como essas técnicas de impressão podem ser utilizadas na frente e no verso da lona, assim como produzir carimbos e estêncil. Os alunos puderam produzir estes materiais, bem como aplicar as técnicas aprendidas em uma sacola confeccionada a partir da lona (Figura 4). 
Figura 4 - Terceiro dia de curso com técnicas de impressão.

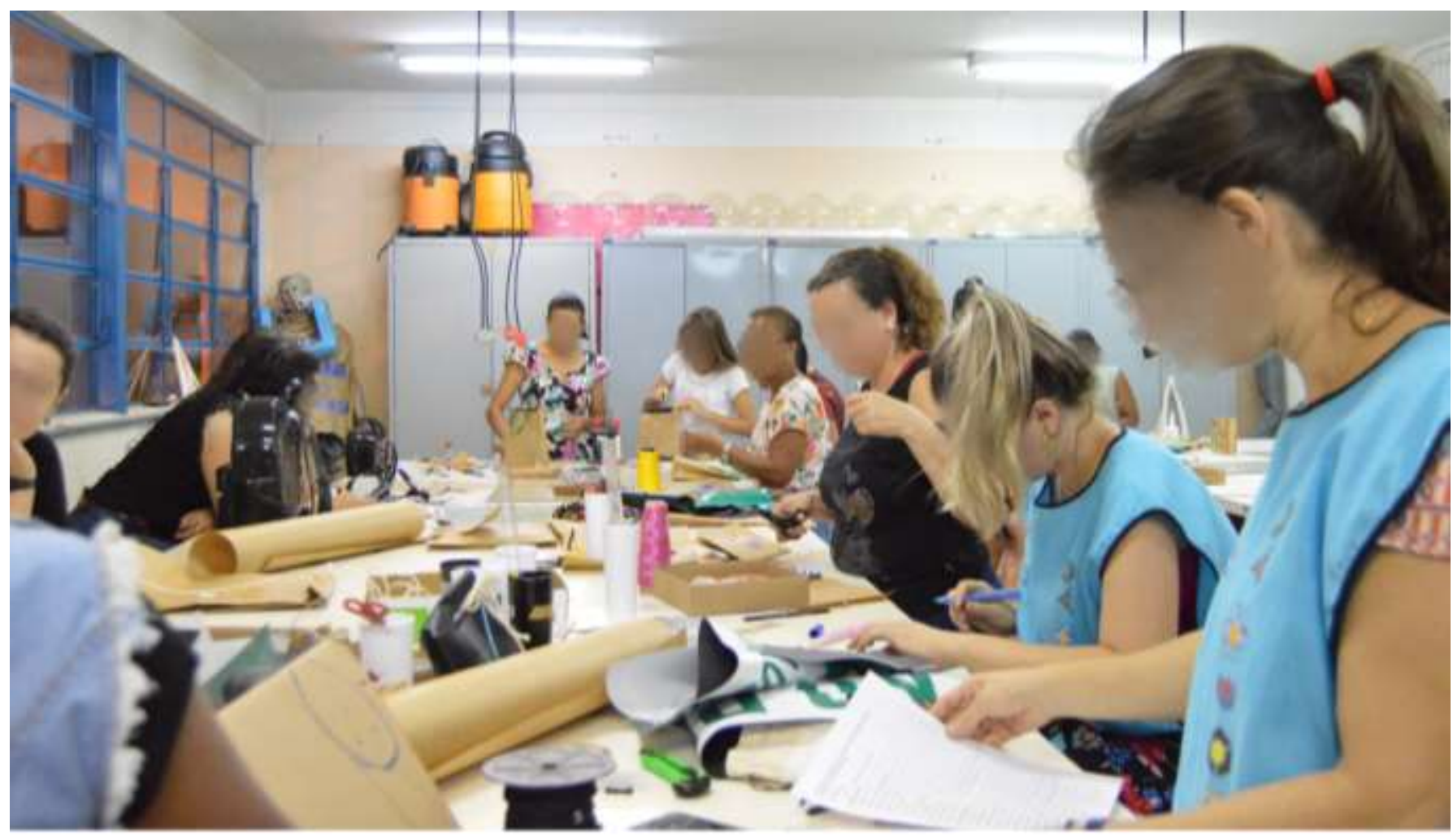

Fonte: Autoras (2021).

No quarto dia os alunos aprenderam as técnicas introdutórias de modelagem para utilizarem na produção das bolsas de lona. Como a maioria dos artesãos já possuíam alguma noção de modelagem e costura, foi possível exigir um pouco mais dos alunos apresentando modelos de produtos mais difíceis.

No quinto dia os alunos tiveram aula de corte e costura intitulado: Corte e costura dos modelos com as principais técnicas necessárias para a compreensão do desempenho dos materiais. Neste dia os participantes do curso confeccionaram 3 peças com a lona e puderam verificar na prática como o material se comporta na máquina de costura industrial e doméstica, bem como perceber a diferença que possui dos tecidos planos, malha e até couro sintético. Como a maioria dos participantes do curso tinham experiência em costura, algumas são profissionais, este dia foi bastante produtivo e os resultados muito promissores.

No último dia de curso os alunos tiveram uma aula sobre embalagem, marca e comercialização, na qual eles aprenderam sobre a importância em se investir no aspecto das embalagens, de ter uma marca e como comercializar os produtos desenvolvidos por meio das redes sociais, método com menor custo atualmente. Na aula prática os artesãos tiveram que desenvolver uma embalagem para os produtos que são produzidos por eles e identificá-los com algum desenho ou texto. Esta atividade permitiu que eles percebessem como o investimento, por menor que seja, no aspecto da embalagem, na sua customização pode fazer a diferença no momento da comercialização e como isso pode chamar a atenção do público consumidor. 
Figura 5 - Embalagens desenvolvidas no curso.

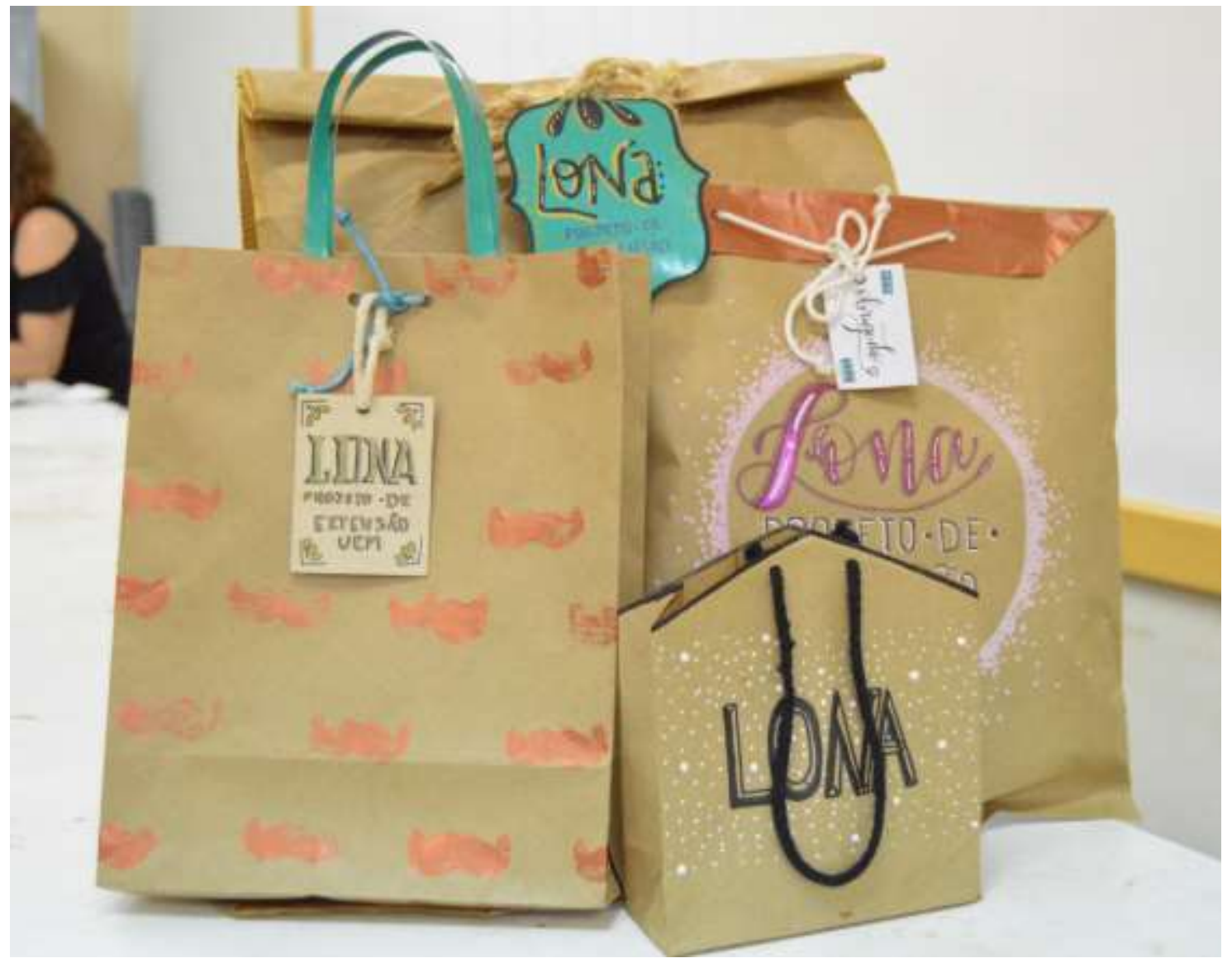

Fonte: Autoras (2021).

Este curso foi oferecido mais duas vezes na cidade de Paiçandu, um atendendo às mães de crianças que frequentam a APAE e outra a um grupo de artesãos de Paiçandu e Água Boa. Em todos os cursos oferecidos houve uma reunião prévia para conhecer os artesãos, perceber quais eram suas expectativas quanto ao curso, bem como conhecer o tipo de produto produzido por eles, desta forma os cursos eram direcionados a realidade de cada grupo. Um exemplo disso foi no curso oferecido aos artesãos de Água Boa e Paiçandu, estes estavam montando um espaço fixo para comercialização dos produtos e solicitaram auxílio quanto a montagem da vitrine e espaço interno da loja. Neste caso foi oferecido também um curso de vitrinismo a fim de capacitá-los a montar sozinhos uma vitrine.

Os cursos tiveram uma boa aceitação pelos artesãos e boa repercussão na região, sendo divulgado nas redes sociais e mídia televisiva. O projeto acabou recebendo muitas doações de lonas e solicitação de produção de produtos para a comunidade interna e externa da universidade, mas como o projeto não visa produção de produtos para comercialização e tampouco tem equipamento suficiente para este tipo de negócio, os pedidos foram redirecionados aos artesãos que já tinham feito o curso.

Interessante observar também é que uma das primeiras artesãs a fazer o curso começou a produzir bolsas em lona, mas também aproveitou o conhecimento aprendido no curso para confeccionar bolsas com outros materiais e está recebendo muitas encomendas.

Os resultados apresentados foram semelhantes aos encontrados por projetos desenvolvidos por universidades em todo o Brasil, como é o caso de Costa et al. (2019), Coutinho et al. (2017), Hermes e Morgenstern (2016), Jung et al. (2015) e Martinussi, Rosa e Goya (2010) e todos apresentaram resultados interessantes e possuem a mesma preocupação social e ambiental.

No entanto é difícil conhecer profissionais brasileiros que utilizam a lona como meio de subsistência, como é o caso da 
Recreate, empresa portuguesa, que utiliza o design como meio de diferenciação de seus produtos, evidenciando o potencial de continuidade destes projetos para contribuir no desenvolvimento social e ambiental.

\section{Conclusão}

A possibilidade de ajudar comunidades de artesãos que possuem o conhecimento do processo produtivo, porém desconhece as possibilidades que o design pode oferecer para o aumento das vendas dos produtos e, consequentemente, da renda das famílias, foi um dos motes principais deste projeto, juntamente com a necessidade de se reaproveitar um material que tem bom potencial de uso, porém sua degradação no meio ambiente é muito lenta.

Considerando que as necessidades dos usuários de banner, muitas vezes são limitadas a poucos dias ou mesmo poucas horas de uso, como por exemplo banners de congressos e eventos. Após um pequeno uso, este material é descartado normalmente ainda em excelente estado e leva muitos anos para se decompor no meio ambiente. Portanto, é possível a aplicação do método utilizado pelo projeto por outros grupos, como ONGs, grupos religiosos entre outros, contribuindo para a geração e/ou o aumento da renda de famílias menos favorecidas.

Neste contexto, este artigo mostrou que o design social e o design ambiental podem contribuir para o aumento da renda das famílias com a produção de diversos tipos de objetos utilizando um material que seria descartado, estendendo, desta forma, o ciclo de vida da lona de banner.

\section{Agradecimentos}

As autoras agradecem a Secretaria de Estado de Ciência, Tecnologia e Ensino Superior - SETI por meio do programa Universidade Sem Fronteiras pelo apoio financeiro ao desenvolvimento do projeto.

\section{Referências}

Abir, S., Abdel-Naby, Azza A. \& Al-Ghamdi (2014). Poly(vinyl chloride) blend with biodegradable cellulose acetate in presence of N-(phenyl amino) maleimides, International Journal of Biological Macromolecules, 70, 124-130, https://doi.org/10.1016/j.ijbiomac.2014.06.033.

Ashby, M. F. \& Johnson, K. (2011). Materiais e design: arte e ciência da seleção de materiais no design de produto. Elsevier.

Baxter, M. R. (2005). Projeto de Produto: Guia Prático para o design de novos produtos (2a ed.). Blücher.

Cardoso, L. J. S., Valente, V. F., Rodrigues, V. T., Pavalk, A. \& Rodrigues, M. N. (2016). Alternativas sustentáveis para reutilização de banners em Universidade do Estado do Pará. In: XXXVI Encontro Nacional de Engenharia de Producão. Anais... João Pessoa, 12 p. Recuperado em 14 março 2021 , de http://www.abepro.org.br/biblioteca/TN_STP_236_374_30378.pdf.

Costa, G. M. M., da Silva, C. de P. F., Oliveira, L. S. da C., Nascimento, J. P., Araújo, N. da S., \& dos Reis, A. S. (2019). Confecção de bolsas a partir do reaproveitamento: um olhar diferente sobre o banner. Revista Brasileira De Educação Ambiental (RevBEA), 14(4), 58-73. https://doi.org/10.34024/revbea.2019.v14.2718

Coutinho, L. D., Mariano, I. P. \& Souza, F. A. (2017) Reaproveitamento de banners na confecção de produtos sustentáveis. In: $5^{\circ}$ Congresso Científico Têxtil e Moda, 2017. Anais... http://contexmod.net.br/index.php/quinto/ article/view/757.

Fullana O. \& Puig R. (1997). Análisis ciclo de vida. Editora Rubes S.L.

Henkel C., Hüffer T. \& Hofmann T. (2019). The leaching of phthalates from PVC can be determined with an infinite sink approach. MethodsX, 6, 2729-2734. https://doi.org/10.1016/j.mex.2019.10.026. https://www-sciencedirect.ez79.periodicos.capes.gov.br/science/article/pii/S2215016119302912?via\%3Dihub

Hermes, L. \& Morgenstern, E. C. (2016). Ecobanner: reaproveitamento sustentável de lonas vinúlicas, pp. 5569-5570. In: Anais do 12º Congresso Brasileiro de Pesquisa e Desenvolvimento em Design. Blucher Design Proceedings, 9 (2). Blucher. 10.5151/despro-pe d2016-0505

Jung, A. A., Saldanha, M. V., Gonçalves, J. A., Tocchetto, M. R. L. \& Dic, C. (2015). PROJETO RElona: Reaproveitamento de Lonas De Banner. In: $4^{\circ}$ Fórum Internacional Ecoinovar. Anais... https://docplayer.com.br/10364735-Projeto-relona-reaproveitamento-de-lonas-de-banner-relona-project-reuse-of-bannercanvas.html.

Kazazian, T. (2005). Haverá a idade das coisas leves: design e desenvolvimento sustentável (2a ed.). Senac, 2005. 
Research, Society and Development, v. 10, n. 4, e26710414081, 2021

(CC BY 4.0) | ISSN 2525-3409 | DOI: http://dx.doi.org/10.33448/rsd-v10i4.14081

Manzini, E. \& Vezzoli, C. (2008). O Desenvolvimento de Produtos Sustentáveis: Os Requisitos Ambientais dos Produtos Industriais. Editora da Universidade de São Paulo.

Martinussi, J. C., Rosa, R. P. \& Goya, C. R. (2010). Projeto Kid Vinil: um estudo de caso para a reutilização de resíduos de lona vinílica. Anais do $9^{\circ}$ Congresso Brasileiro de Pesquisa e Desenvolvimento em Design.

Najeliski, D. N., Palhano, A. P., \& Matoso, L. G. (2017). Estudo de Viabilidade da Reutilização de Banners de Lona na Produção de Móveis. Sustentabilidade em Debate, Brasília, 8(2), 60-74. http://periodicos.unb. br/index.php/sust/article/view/16647.

Peltier, F. \& Saporta, H. (2009). Design sustentável: caminhos virtuosos. Editora Senac.

PlasticsEurope (2020). Plastics - The Facts 2020, An Analysis of the European Plastics Production, Demand and Waste Data. https://www.plasticseurope.org/en/resources/publications/4312-plastics-facts-2020.

Recreate by Forma (2021). https://www.recreate.pt/.

Rocha, J. C., Rosa, A. H. \& Cardoso, A. A. (2009). Introdução a Química Ambiental (2a ed.). Bookman.

Rutiaga, M. O., Galan, L. J., Morales, L. H; Gordon, S. H., Imam, S. H; Orts, W. J., Glenn, G. M. \& Niño, K. A. (2005). Mechanical property and biodegradability of cast films prepared from blends of oppositely charged biopolymers. Journal of Polymers and the Environment, $13(2), 185-191$.

Silva, E. L. \& Menezes, E. M. (2001) Metodologia da Pesquisa e Elaboração de Dissertação (3a ed.), Laboratório de Ensino a Distância da UFSC. 